\title{
SOLOMBRA: SOMBRA E LUZ
}

\section{SOLOMBRA: SHADOW AND LIGHT}

Delvanir LOPES ${ }^{50}$

RESUMO: A última obra publicada em vida por Cecília Meireles carrega em si uma aura de ambivalência, evidenciada nos seus poemas. Se a palavra escolhida para título da obra solombra - é por si só enigmática e comporta os sentidos de luz e de sombra, essas constatações ganham força quando analisados os versos e a epígrafe. Apesar da grande maioria dos estudiosos de Solombra entenderem-na como obra voltada à tristeza, à sombra, à melancolia, acreditamos na possibilidade de outro viés, movido pela esperança e pela luminosidade, ainda que mais timidamente. Este ensaio busca identificar alguns pontos dessa possível leitura da obra ceciliana, mostrando que a sombra, nela, relaciona-se à luz e vice-versa.

PALAVRAS-CHAVE: Poesia brasileira; Modernismo; Solombra; Sombra; Luz.

ABSTRACT: The last work of Cecilia Meireles published in life brings with itself an aura of ambivalence, which is evident in its poems. If the word chosen to be the title of the work - solombra - is by itself enigmatic and admits the meanings of light and shadow, those evidences becomes stronger when the verses and the epigraph are analyzed. Although many scholars involved in the study of Solombra comprehend this book directed to sadness, shadow and melancholy, we believe in the possibility of

\footnotetext{
${ }^{50}$ Doutorando do Programa de Pós-Graduação em Letras (Bolsista FAPESP) - Faculdade de Ciências e Letras - Universidade Estadual Paulista (UNESP), campus de Assis - CEP 19806-900 - Assis - SP Brasil - E-mail: itapolissp@ig.com.br
} 
another point of view, which is moved by hope and luminosity, even though those aspects are more timid. This essay seeks to identify some points of this possible reading of Cecilia's work, showing that the shadow only is possible because of the light and vice versa.

KEYWORDS: Brazilian poetry; Modernism; Solombra; Shadow; Light.

Tenho pena de ver uma palavra que morre. Me dá logo vontade de pô-la viva de novo. Solombra [...] era o título que eu buscava e a palavra viveu de novo.

(MEIRELES apud BLOCH, 1989, p.33)

Solombra, último livro editado em vida pela poetisa Cecília Meireles, em 1963, tem sido objeto de poucos estudos aprofundados por parte da crítica. No entanto, por ser uma obra que fecha toda uma trajetória poética e de vida, adquire grande importância. "Sendo a sua última obra publicada em vida, pode-se considerá-lo como seu testemunho final: o livro torna-se um pronunciamento estético chave no conjunto da obra ceciliana [...]" (BELON, 2001, p. 10). Boberg concorda com Belon ao afirmar que "Solombra constitui-se na síntese final e plena de toda a trajetória filosófica e mística idealizada muito antes de Viagem." (BOBERG, 1989, p. 209; grifo do autor). Mais recentemente, Ana Maria Lisboa de Mello (2002, p.193) reitera:

Solombra é, no universo ceciliano, a obra em que o eu-lírico parece atingir o ápice de uma caminhada mística, que se revela em atitude acentuadamente ascética, e assinala, do primeiro ao último poema, o desprendimento progressivo do plano material. 
Embora nas citações anteriores fique evidente o quão importante é a Solombra no universo de Cecília Meireles, ainda são poucas as teses e estudos que sobre ela se debruçam com mais vagar, contrariamente a outras obras cecilianas, como Vaga música e Mar absoluto. Mas há alguns trabalhos relevantes, como é o caso da tese de Belon (2001), da apresentação de Hansen (2007) durante o Centenário do nascimento de Cecília Meireles e do capítulo reservado a Solombra por Ana Maria Lisboa de Mello em seu Poesia e imaginário (2002), sem nos esquecermos da publicação jornalística de Chrisani Mendes (1964) e do capítulo final de $O$ mundo contemplado, de Darcy Damasceno (1967). Mesmo assim, são parcos os estudos para uma obra que conta quase meio século desde a sua edição.

Poderíamos conjecturar que nas palavras de Leila Gouvêa (2001, p. 48) de que se trata da obra mais abstracionista de Cecília possa estar um dos motivos que afasta os críticos de um estudo mais profundo dessa obra. Poderíamos supor ainda que tal obra fosse um retorno à atmosfera mística, ao tempo considerado ciclicamente, ao "mais do mesmo", a todos os temas já trabalhados pela escritora e que se manifestaram em sua obra poética. Felizmente não é assim e alguns estudiosos de Cecília têm percebido uma renovação na compreensão da poetisa. Este ensaio busca acrescentar Solombra nessas novas considerações, sobretudo mostrando que à melancolia, sempre tão explorada pela crítica, se alia a esperança e a luminosidade. A obra mostra um caráter paradoxal, unificando o mistério à revelação, o terreno ao espiritual, o abstrato ao concreto. A poesia ceciliana é enigmática para clarificar o ser.

$\mathrm{Na}$ verdade, poucas obras, como a de Cecília, podem ser consideradas como um claro enigma. A autora dá impressão de explicar tudo, desfazendo os emaranhados, mas a música de seus versos tende para o translúcido que dissolve a nitidez dos contornos sugeridos pelas palavras dispostas em metros diversos e também em versos livres, com o uso de rimas toantes, consoantes, sem amarras, 'libérrima' e exata, como disse Manuel Bandeira. (AMÂNCIO, 2001, p. D1).

Na leitura dos poemas a clarificação se dá aos poucos, digerindo as imagens que 
a poesia forma, não numa interpretação imediata de suas palavras, mas buscando entender o que é sugerido, evocado tão concisamente em cada novo verso. Assim, na finitude o eu-lírico busca o infinito, no real busca o invisível, no efêmero busca o eterno, na morte busca a transcendência e assim o universo ceciliano de Solombra vai se abrindo, sugerindo pistas.

O que pretendemos com este ensaio é mostrar um novo viés da obra ceciliana, destoando da crítica e fugindo da obviedade das palavras. Assim é que solombra, termo arcaico encontrado ao acaso e que, nesta concepção, remete à sombra, obviamente diz muito mais do que isso quando é levado para a poesia. Enquanto símbolo, o vocábulo solombra mais esconde do que clarifica. Por isso, consideramos que a pista que a poetisa nos dá quando, em entrevista a Pedro Bloch (1989, p. 210), afirma que solombra refere-se somente à sombra, por si só já acarreta a dúvida e não a certeza. A palavra solta significa sombra, mas em Solombra ganha uma aura de ambivalência e de dúvida. A maior parte da crítica relacionou, a partir da declaração de Cecília, sombra à melancolia, à tristeza, à dor da ausência, ao desajuste diante do mundo.

Em Solombra (1963), publicado um ano antes de sua morte, a temática de sua poesia se condensa numa atmosfera outonal e melancólica de sombra e silêncio. Mais do que nos livros anteriores, com efeito, a estilística do silêncio se desenvolve num mundo de sombra e pura espiritualidade. (AZEVEDO FILHO, 1970, p. 185).

Porém, outros leitores de Cecília colocaram em dúvida a clareza do título da obra, como é o caso de Carlos Drummond de Andrade:

SOLOMBRA - Sombra. Sombra só? Sol e Sombra? Sol em sombra? Em torno dela multiplicam-se as conotações que se gravam em nós, em som, forma, côr e sugestão e também em signos que temos de decifrar continuamente pois são símbolos de interrogações, especulações transcendentes. (ANDRADE apud MENDES, 1968).

A leitura de Cecília Meireles, apesar de parecer extremamente clara e auto- 
explicativa, não traz um único viés interpretativo, mas salienta a riqueza de várias possibilidades de leitura, como tão bem escreveu Drummond. Nesse sentido, aproveitamos para deixar de lado a "verdade" aceita sobre Solombra, de que se trata de uma obra voltada à melancolia e ao silêncio. Segundo Maria Schuartz:

A obra de Cecília é de uma impressionante unidade, o que não significa facilidade ou uniformidade, como afirmaram alguns. Ao contrário: dificulta ao crítico o recorte, torna mais árido o estudo segmentado por livro e revela uma fidelidade essencial a um imaginário poético. (SCHUARTZ apud AMÂNCIO, 2001, p. D1).

Sendo assim, Sol-ombra define bem a missão enigmática ceciliana, misteriosa e clara, dual ao mesmo tempo. Enquanto o obra é instrumento de revelação, é também a que esconde. Às vezes nos dá uma clareira, nos permite um foco de luz em meio à escuridão. E quando pensamos que estamos diante do conhecido, se mostra novamente enigmática e nos obscurece o pensamento. Cecília trouxe o termo solombra de novo à vida, livrou-o da masmorra, desencobriu-o. A palavra escolhida "ao acaso" é perfeita: expressa o binômio da ausência/ presença, carrega em si a ambiguidade e nos lança em uma série de conjecturas, além do que se alia ao jogo paradoxal de Solombra: sombra e claridade.

Analisaremos a dualidade de Solombra em três momentos: no título, na epígrafe da obra e em um de seus poemas. O título - Solombra - permite essa compreensão paradoxal, embora Cecília tenha nos alertado de que o termo se refere somente à sombra. A etimologia da palavra tem origem controversa, indicando que o arcaísmo soombra parece ter origem no latim vulgar sulumbra (sub illa umbra 'sob esta sombra'). "O $-s-$, agregado somente em português e espanhol, seria resultado do influxo de sol e seus derivados, por sol e sombra [...] serem conceitos relativos, opostos e constantemente acoplados." (HOUAISS, 2002) É desse modo que em Solombra os termos luz e sombra estão atrelados e são indissociáveis. A sombra é resultado da luz que se apaga sobre algum objeto. Assim, para haver a sombra, a luz não pode não 
existir, pois caso isso aconteça é como se a sombra desaparecesse, concomitantemente. No entanto, há luz na sombra e escuridão na luminosidade:

Sobre um passo de luz outro passo de sombra.

(MEIRELES, 2001, p. 1277).

Ó Luz da noite, descobrindo a cor submersa

pelos caminhos onde o espaço é humano e obscuro

e a vida um sonho de futuros nascimentos.

(MEIRELES, 2001, p. 1273).

O paradoxo da expressão "luz da noite" pode sugerir a aparente falta de nexo, a contradição das ideias, o absurdo, quando referentes à opinião comum, já que na noite o que se espera é encontrar a escuridão. Mas Cecília Meireles revela-se extremamente engenhosa com as palavras e aliando o que, aparentemente, é contraditório, nos leva a pensar. $\mathrm{Na}$ verdade, em poucas palavras ela encerra um profundo sentido ao seu livro Solombra, alimentando as indagações. Ou seja, esconde e clareia ao mesmo tempo.

É dessa maneira que entendemos o título da obra, caminho da luz à sombra ou vice-versa. "O mistério todo está nisto. Este momento da emoção em que há claridade, mas tudo envolto na penugem da noite - a vida se recolhendo, se revisando." (AYALA, 1964, p. 20). Sendo assim, a partir do título podemos conjecturar que não se trata de um livro voltado apenas à melancolia, à tristeza, à solidão, à sombra e à morte, como argumentam muitos críticos. No nosso entender, Cecília Meireles não se volta exclusivamente a esses temas em suas obras de forma finalista e enfadonha, mas utilizase de tais recursos para demonstrar a possibilidade do devir, da transformação.

A respeito da tristeza, que podemos inserir nas conotações de sombra, eis o que a poetisa, em carta a Cortes-Rodrigues, diz: "Mas a tristeza não é o que me faz sofrer, propriamente. Tenho observado muito isso. A tristeza deixa-me pensativa, faz-me entender muitas coisas, é uma espécie de corredor por onde alcanço grandes salas misteriosas." (MEIRELES, 1998, p. 100).

Ainda que Cecília não seja explicitamente "luminosa" em suas poesias, essa claridade transparece de forma contundente em Solombra. Nesse sentido, o caminho 
traçado é o mesmo encontrado na citação abaixo, ao discorrer sobre a obra Metal rosicler:

O metal rosicler tem cor de crepúsculo. A cor negra da noite que começa sucede o crepúsculo, a madrugada que finda antecede o nascer do sol. Ambiguidade do lusco-fusco que é sempre prenúncio de algo, passagem que inicia alguma coisa, ciclos de luz e treva que se repetem. O momento do crepúsculo é o da luz manifestando-se em matizes diferentes, tornando tudo como que 'ensanguentado', mudando a paisagem, como que se preparando ou despedindo-se de algo. Crepúsculo da vida que se vai, prenúncio da vida que se anuncia, o crepúsculo é sempre transição, como a existência que sempre está contrapondo tempo e eternidade, morte e vida, angústia e transcendência, ser e nãoser, mudar ou permanecer. (LOPES, 2004, p. 211).

A sombra e a luminosidade que o jogo de palavras ceciliano propõe levam à análise do interior humano, que também é ambíguo e desconhecido. Entrar em si é arriscar-se no ignorado, em que lampejos de luz surgem repentinamente e logo em seguida desaparecem, engolidos pelas sombras. Assim trabalha nosso pensamento. Vamos da sombra à luz (ou vice-versa) e novamente à sombra, e novamente à luz, incessantemente. Estar num momento específico não implica, necessariamente, em nãoestar em outro, porque eles se completam e não se excluem. A dúvida leva à certeza, que por sua vez se desfaz quando surgem outras dúvidas. O sujeito lírico de Solombra sempre almeja a luz: "Dizer com claridade o que existe em segredo." (MEIRELES, 2001, p. 1265).

A sombra ainda pode associar-se ao duplo, como se o eu fosse dividido em sol (parte positiva) e sombra (parte negativa) e necessitasse sempre completar-se, tornar-se total existencialmente. A sombra leva o eu-lírico "a representar a sua fragmentação e a buscar, consequentemente, uma completude e uma totalidade, a partir do diálogo lírico com 'um outro', um alter ego dissonante." (MELLO, 2002, p.144). Desse modo, o eu e seu duplo, embora duas facetas distintas, são complementares e representam o mesmo 
"ser". Em Solombra o eu-lírico trava um diálogo com um "tu" que permeia toda a obra, como se por ele buscasse sua própria compreensão.

Só tu sabes usar tão diáfano mistério:

trajo sem ruga, espelho dedicado ao sono, estrela sobre a duna em hora ausente do Homem.

(MEIRELES, 2001, p. 1269).

A crítica procura explicar o Outro, o Tu, de diferentes formas. Ana M. L. de Mello (2002. p. 239) acredita que o outro se situa no plano do sagrado, transcendental, com quem o eu-lírico busca contato. Para Hansen, "o 'tu' corresponde à 'memória indefinida e inconsolável' que vem pelas noites assombrar o eu sob a sua sombra" (HANSEN, 2007, p. 41). Boberg (1989, p. 211) assinala que "o espírito elegíaco dos poemas constata a ausência de um ser ansiosamente procurado e essa ausência é dolorida." Por fim, Ayala (1964, p.20) diz, poeticamente:

Ela começa o livro se dirigindo a alguém, a alguma coisa que encerra tudo, que pode ser o gênero humano, a comunhão dos santos ou Deus mesmo. Alguma coisa que pode ser a nossa consciência de existir, que pode ser o nosso medo, esta forma crispada com que enfrentamos cada respiração, sabendo das nossas possibilidades e dos nossos limites.

Exceto em Hansen, o Outro a quem o sujeito lírico se dirige identifica-se com o sagrado, com Deus, com um ser indizível. Em todas as soluções encontradas pelos críticos, o que fica claro é que há uma atração do eu-lírico pelo Outro, do qual procura extrair o sentido e a verdade, razão por que sempre o questiona. Ao que parece, tirando da sombra do "tu", o eu-lírico descobre a si mesmo.

A epígrafe do livro também nos fornece mais informações sobre o caráter dual de Solombra:

Levantei os olhos pra ver quem falara. Mas apenas ouvi as vozes combaterem. E vi que era no Céu e na Terra. E disseram-me: Solombra. 
(MEIRELES, 2001, p. 1262).

Uma vez que a epígrafe serve de tema ao assunto ou resume o sentido e a motivação de uma obra, em Solombra, do mesmo modo, mostra a ambiguidade da existência e sugere que a obra não terá apenas uma voz, a de escuridão e tristeza, mas nela poderá ser ouvida outra, com a mesma intensidade, que tratará da esperança e das possibilidades da transcendência do ser.

O eu-lírico ouve duas vozes combaterem, uma no céu e outra na terra, mas não vê de onde elas partem. Enquanto as ouve está em silêncio, que é quebrado apenas pelo som das vozes combatendo, como se estivessem em guerra. O eu-lírico está no percurso do mundo, está no tempo e é justamente por isso que é capaz de ouvir as vozes. Primeiro as ouve, depois fala nos versos de Solombra, como se a dialogar com elas.

As vozes, uma no céu e outra na terra, se opõem. O céu é considerado princípio ativo e masculino e a terra, princípio feminino e passivo; o céu indica a luminosidade e a transcendência, a terra indica a morte e a escuridão. E o eu-lírico está, nesta epígrafe, entre o céu e a terra. É o ser angustiado, dividido entre a matéria e o espírito, e indeciso sobre a qual voz deve dar mais atenção.

Podemos ampliar nossa compreensão sobre o conteúdo da epígrafe de Solombra fazendo uso de algumas ideias do filósofo alemão Martin Heidegger (1888-1976) e seus escritos sobre a poesia ${ }^{51}$, nos quais deixa claro que é o ser que se revela ao homem e não o contrário. Mas, como o desvelar do ser se dá pela linguagem da poesia, o homem deve ter atitude de silêncio para ouvi-lo, abandonando-se nesse ser. Percebemos que na epígrafe do livro ceciliano, o eu-lírico não diz nada. $\mathrm{Na}$ realidade quem diz alguma coisa são as vozes, juntas, como se fossem uma só coisa, um só ser - "E disseram-me: Solombra." A atitude do sujeito lírico é esperar pelas palavras das vozes.

Cecília, em entrevista a Walmir Ayala, afirma: "Parece que os poemas são apenas o resultado de um diálogo do espírito com o mundo. Do meu espírito ou do Espírito. [...] De permeio está, naturalmente a palavra, por ser a forma de expressão literária." (AYALA, 1958, não paginado). A palavra é o instrumento que permite a

51 Cf. HEIDEGGER. Arte y poesía. Trad. Samuel Ramos. México: FCE, 2006; Carta sobre o Humanismo. Trad. Rubens E. Frias. São Paulo: Centauro, 2005; A caminho da linguagem. Trad. Márcia Sá C. Schuback. Petrópolis, RJ: Vozes, 2003. 
comunicação entre os mundos e o poeta o indivíduo que trava uma relação diferenciada com ela. Na perspectiva simbolista, a palavra faculta ao poeta a capacidade de entender o enigma das "correspondências". Nas palavras de Baudelaire: "o que é um poeta, senão um decifrador?" (GOMES, 1994, p. 23)

A linguagem cifrada não é direta, mas não está separada da realidade empírica, por isso num poema tudo pode ser visto como linguagem cifrada, tudo é linguagem da transcendência, mas para que se torne cifra depende de uma existência que a interprete, atualizando-a em sua liberdade, que é o caso do poeta. (LOPES, 2004, p. 129).

Não é qualquer indivíduo que pode ouvir as vozes, mas só aquele que está disposto a ouvi-las. Heidegger esclarece que a figura do poeta é privilegiada nesse sentido, uma vez que ele "está expuesto a los relámpagos de Dios" (HEIDEGGER, 2006 , p. 105) ${ }^{52}$. E a linguagem em que o ser habita é a linguagem poética e criativa. Para encontrá-lo, é preciso abandonar-se nele, habitar no ser.

'Habitar poéticamente' significa estar en la presencia de los dioses y ser tocado por la esencia cercana de las cosas. Que la existencia es 'poética' en su fundamento quiere decir, igualmente, que el estar instaurada (fundamentada) no es un mérito, sino una donación. (HEIDEGGER, 2006, p. 104) ${ }^{53}$.

O poeta compreende a existência humana, mas isso só lhe é facultado se ele estiver acima dos homens e abaixo dos deuses, ou "projetado para fora" de si mesmo: "El poeta mismo está entre aquéllos, los dioses, y este, el pueblo. Es un 'proyectado fuera', fuera en aquel entre, entre los dioses y los hombres." (HEIDEGGER, 2006, p.

\footnotetext{
52 "está exposto aos relâmpagos de Deus" (tradução nossa)

53 "Habitar poeticamente" significa estar na presença dos deuses e ser tocado pela essência próxima das coisas. Que a existência é "poética" no seu fundamento quer dizer, igualmente, que o estar instaurada (fundamentada) não é um mérito, mas uma doação. (tradução nossa)
} 
$108)^{54}$. Aqui também podemos perceber certa semelhança com a epígrafe de Solombra, já que o eu-lírico se encontra entre as vozes combatentes. Ele está em meio ao conflito, disposto a ouvir o que as vozes têm a dizer e transmitir aos homens.

Enfim, o poeta acaba ouvindo as vozes dizerem juntas "solombra". A voz da transcendência, da eternidade, não é mais importante do que a voz que vem da terra, indicando a negatividade, a solidão, a tristeza, o sofrimento. A existência não pode ser reduzida a apenas uma das instâncias, portanto. $\mathrm{O}$ homem sempre estará dividido entre as duas forças que combaterão e deve, do mesmo modo, estar aberto para ouvi-las, uma vez que acabam agindo sempre juntas, como luz e sombra, como sol-ombra.

Completando o raciocínio desenvolvido até agora, em que mostramos a possibilidade da luminosidade no título e na epígrafe de Solombra, vejamos de que modo é trabalhado o sentimento de esperança em alguns versos, em contraposição às considerações de que se trata de uma obra voltada ao passado, à dor e a ausência. A compreensão da temporalidade, outra mola mestra da poética ceciliana, também divide a crítica. Se para alguns é uma aceitação simples do tempo que foge, para outros é a esperança na sobrevivência que leva ao abandono das prisões corporais.

Diante de um mundo que sabe precário e misterioso e onde as coisas são todas transitórias e inexplicáveis, a atitude do poeta se resolve em estóica aceitação, que não é passiva escolha, mas paciente aprendizagem, cujas raízes talvez só pudéssemos encontrar na afinidade de seu pensamento com os filósofos orientais e em sua inata predisposição para um responsável enrijecimento da alma. [...] A fugacidade e a inconsistência de todas as coisas têm sido objeto de reflexão na poesia de todos os tempos. Na obra ceciliana, porém, não nos surpreende por sua constância, mas pelo concerto entre uma tal constatação e a resposta vital que lhe é dada. (OLIVEIRA, 1966 apud GOUVÊA, 2007, p. 131).

\footnotetext{
${ }^{54} \mathrm{O}$ próprio poeta está entre aqueles, os deuses, e este, o povo. É um "projetado para fora", naquele entre os deuses e os homens. (tradução nossa)
} 
A poetisa, portanto, aprende com o tempo que lhe escapa das mãos. Em Solombra não se resigna a aceitar o seu destino e o tempo que passa, mas o questiona, com vistas ao futuro, que desembocará na morte. Na verdade, enquanto existente no mundo o eu-lírico se projeta no que está por vir e angustia-se por perceber o limite que o tempo lhe impõe.

O poema quatro ilustra com informações importantes as considerações acerca da possibilidade do futuro e do desejo de abandono dos limites:

Quero uma solidão, quero um silêncio, uma noite de abismo e a alma inconsútil, para esquecer que vivo - libertar-me

das paredes, de tudo que aprisiona; atravessar demoras, vencer tempos pululantes de enredos e tropeços.

Quebrar limites, extinguir murmúrios, deixar cair as frívolas colunas de alegorias vagamente erguidas.

(MEIRELES, 2001, p. 1265).

Nessas três estrofes a ideia principal é o desejo do eu-lírico libertar-se "de tudo o que aprisiona”. E o que o aprisionaria? Como vimos na análise da epígrafe, o eu-lírico decifra a sua existência quando se dispõe a ouvir as vozes que combatem no céu e na terra, quando está em silêncio, na solidão.

A solidão é um sentimento que por si só não existe, mas somente quando em relação ao outro. Somos solitários quando nos consideramos um ser-entre-outros. Estar na solidão não é algo que agrade a ninguém, embora nos versos acima o eu-lírico a deseje: "quero uma solidão, quero um silêncio". Mais uma vez nos valemos das ideias heideggerianas para nos auxiliar na decifração.

Heidegger argumenta que quando entre-os-outros a preocupação das pessoas é com as coisas do mundo, e disputar sobre quem é o maior ou o melhor e desse modo 
não é possível que se encontre o verdadeiro ser das coisas. Em contrapartida, o eu-lírico não pode se afastar do mundo, uma vez que necessita dos outros e das coisas para chegar à compreensão do ser. O eu-lírico deve estar no mundo, mas não ser do mundo.

Em alguns momentos, contudo, o eu-lírico deseja a solidão, como meio de libertação do mundo que o aprisiona. Estar só é caminho para a autêntica existência, já que o eu-lírico está questionando-se diante da existência. Por isso, podemos entender "o solipsismo existencial [...] exatamente o oposto do solipsismo clássico: não uma tímida retirada do mundo, mas uma ousada descoberta e reapropriação deste.” (RÉE, 2000, p. 39).

O verbo "quero", mesmo no presente do indicativo, volta-se ao futuro e mostra a ambição, a esperança do sujeito lírico. O desejo da "solidão", do "silêncio", da "noite de abismo" e da "alma inconsútil" revela, não a negatividade, mas a sabedoria do eu-lírico que reconhece nesses estados a possibilidade de libertação e de desvelamento do ser.

O mesmo acontece com o sentimento de morte - "para esquecer-me que vivo" que leva o eu-lírico a uma compreensão mais elevada da existência, em que as coisas do mundo perdem seu sentido. Daí o desejo de, pelo silêncio e pela solidão, libertar-se dessas coisas mundanas que aprisionam, quebrando os "limites", as "paredes", inclusive as temporais - "Atravessar demoras, vencer tempos/ pululantes de enredos e tropeços."

O eu-lírico permanece sempre no entre, nem está na luz ou sombra, nem na dor da ausência ou na completa realização das suas possibilidades. Está sempre no devir, em processo, e isso é o que torna sua existência tão particularizada, repleta de experiências que só ele pode viver. Assim, o desejo do eu-lírico pelo "silêncio" e pela "solidão", pela "noite de abismo e alma inconsútil", pelo esquecer-se que vive, não mostra tais sentimentos como pontos de chegada, mas sim como pontes para a libertação, para a quebra de limites do mundo na descoberta do verdadeiro ser. Paradoxalmente, o mergulho na angústia é que possibilita o momento da transcendência. Em outras palavras, entrar na sombra é o que permite atingir a luz.

Solombra expõe em todas as instâncias, seja no título, seja na epígrafe, seja nos versos da obra, uma constância: o paradoxo. Ainda que trabalhe com luz e sombra, com a clarificação e o encobrimento de enigmas, com o real e o abstrato, a obra ceciliana não considera nenhum desses momentos como excludente do outro, mas sim como mantenedores da unidade de Solombra, que não teria a mesma força poética e sugestiva 
se fosse voltada a apenas um dos lados. E a beleza maior está nisso: conciliar o aparentemente oposto, mostrar a relatividade dos conceitos e das verdades consideradas absolutas e amplamente aceitas quase sem questionamento.

Assim, se em Solombra a aura de melancolia, de dor, de solidão e de sofrimento parecem encobrir qualquer outra interpretação, nos surpreendemos quando, tirando as nuvens, passamos a enxergar outro viés que por estar diluído nos versos e não ser tão explícito, permanece na sombra e não é desvelado. Desse modo, as considerações acerca do fazer poético ceciliano também se renovam e se ampliam.

\section{REFERÊNCIAS}

AMÂNCIO, M. Cecília Meireles: um claro enigma. O Estado de São Paulo. São Paulo, 24 Jun 2001, Caderno 2, Cultura, p. D1.

AZEVEDO FILHO, L. Poesia e estilo de Cecília Meireles. Rio de Janeiro: J. Olympio, 1970 .

AYALA, W. Solombra: um livro de magia. Leitura, p.20, Janeiro 1964.

A véspera do livro: obra poética de Cecília Meireles. Correio da Manhã. Rio de Janeiro, 30 Nov 958. Não paginado.

BELON, A. R. A poesia de Cecília Meireles em Solombra. Tese (Doutorado) Faculdade de Ciências e Letras, Universidade Estadual Paulista, Assis, 2001.

BOBERG, H. T. R.. O canto e a lida - percurso esotérico e místico da poesia de Fernando Pessoa e Cecília Meireles. Dissertação (Mestrado) - Faculdade de Ciências e Letras, Universidade Estadual Paulista, Assis, 1989.

BLOCH, P. Pedro Bloch entrevista Cecília Meireles. In: Vida, pensamento e obra de grandes vultos da cultura brasileira: entrevistas. Rio de Janeiro: Bloch, 1989. p.31-36.

DAMASCENO, D. Cecília Meireles: o mundo contemplado. Rio de Janeiro: Orfeu, 1967.

GOMES, A. C. O simbolismo. São Paulo: Ática, 1994.

GOUVÊA, L. V. B. Cecília Meireles: mais que o aço... poderosa. TJ. São Paulo: Imprensa Oficial do Estado, 11 Nov 2001, n. 11, p. 42-50. 
(Org.). Ensaios sobre Cecília Meireles. São Paulo: Humanitas (FFLCHUSP)/FAPESP, 2007.

HANSEN, J. A. Solombra, ou a sombra que cai sobre o eu. In: GOUVÊA, L. V. B.

(Org.). Ensaios sobre Cecília Meireles. São Paulo: Humanitas (FFLCHUSP)/FAPESP, 2007. p.33-48.

HEIDEGGER, M. Hölderlin y la esencia de la poesía. In: Arte y poesía.

México/Buenos Aires: Fondo de Cultura Económica, 2006. p. 93-110.

HOUAISS - Dicionário Eletrônico da Língua Portuguesa. Editora Europa, Março de 2002, parte da Revista do Cd-Rom n. 82, 1 CD-ROM.

LOPES, D. A poética de Cecília Meireles e a relação com a filosofia da existência ou da angústia e transcendência em Metal Rosicler. Dissertação (Mestrado) - Faculdade de Ciências e Letras, Universidade Estadual Paulista, Araraquara, 2004.

MEIRELES, C. Poesia completa. Rio de Janeiro: Nova Fronteira, 2001.

MELLO, A. M. L. de. Viagem aos confins da noite: Solombra. In: Poesia e imaginário. Porto Alegre: EDIPUCRS, 2002. p.191-239.

MENDES, C. A metáfora e Cecília Meireles (Estudo crítico de Solombra). Jornal de Letras, Rio de Janeiro: Faculdade de Direito de Petrópolis, Agosto 1968.

RÉE, J. Heidegger. História e verdade em Ser e tempo. Tradução José Oscar de A. Marques \& Karen Volobuef. São Paulo: UNESP, 2000.

SACHET, C. (Org.). A lição do poema - cartas de Cecília Meireles a Armando CortesRodrigues. Ponta Delgada: Instituto Cultural de Ponta Delgada, 1998.

Artigo recebido em 10/04/2010. Aceito para publicação em 26/05/2010. 